\title{
Impact of COVID-19 on cancer management in military hospitals of Saudi Arabia
}

\author{
Omar Al Zahrani, MD, Ismail Ghorbel, MD, Osama Mukhtar, MSc, Muneera Almajed, MD, Hoda M. Abdelazim, MD, \\ Muhammad N. Hasan, MD, Ahmad Mostafa, MD, Aisha A. Al Harbi, MD, Ali Bajouda, MD.
}

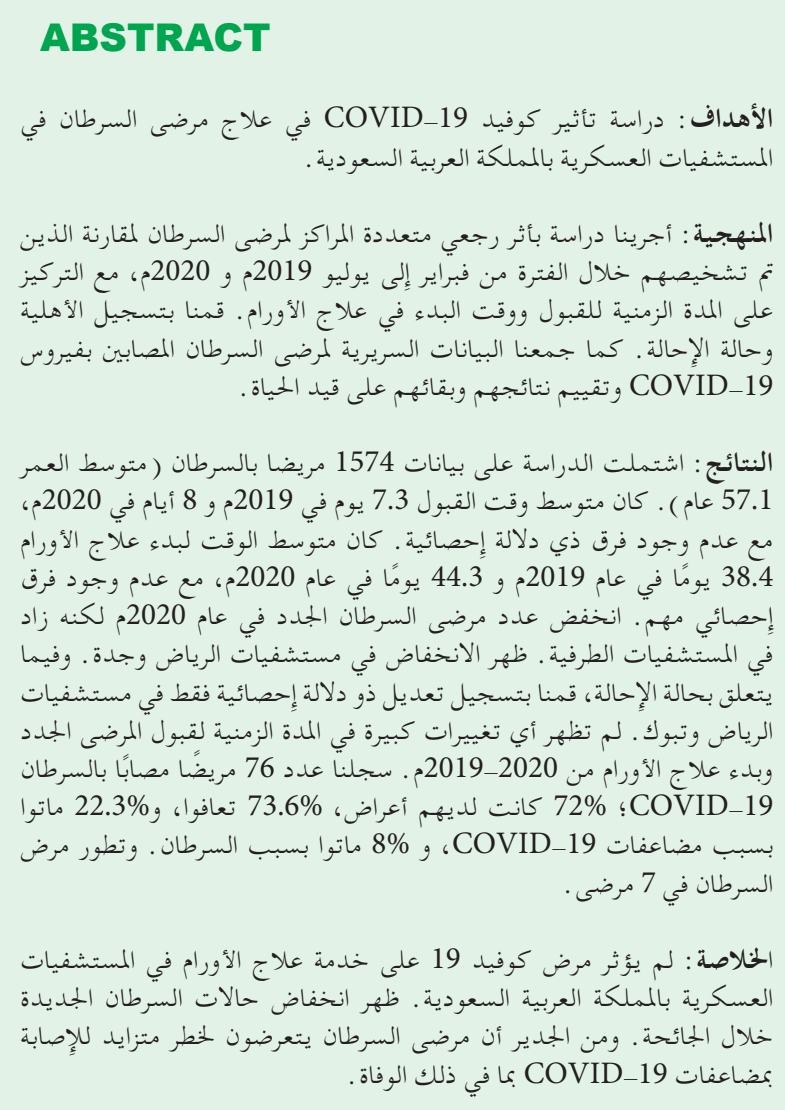

Objectives: To evaluate the impact of COVID-19 on cancer management in Saudi Arabia's military hospitals.

Methods: This multi-centric, retrospective study compared cancer patients diagnosed from FebruaryJuly 2019 and 2020, focusing on the time duration for acceptance and time for oncologic treatment initiation. Eligibility and referral status were recorded. Clinical data of COVID-19-positive cancer patients were collected and evaluated their outcomes and survival.

Results: Data of 1574 cancer patients (mean age, 57.1 years) were collected. Mean time for acceptance was
7.3 days in 2019 and 8 days in 2020, with no statistically significant difference. Mean time for oncology treatment initiation was 38.4 days in 2019 and 44.3 days in 2020, with no statistically significant difference. The number of new cancer patients decreased in 2020 but increased in peripheral hospitals. It decreased in Riyadh and Jeddah hospitals. Concerning referral status, a statistically significant modification was recorded only in Riyadh and Tabuk hospitals. No significant changes observed in time duration for acceptance of new patients and oncology treatment initiation from 2019-2020. A total of 76 COVID-19-positive cancer patients recorded; $72 \%$ were symptomatic, $73.6 \%$ recovered, $22.3 \%$ died due to COVID-19 complications, and $8 \%$ died due to cancer; cancer progressed in 7 patients.

Conclusion: COVID-19 did not affect oncology service in Saudi Arabia's military hospitals. New cancer cases reduced during the pandemic. Cancer patients are at increased risk for COVID-19 complications, including death.

Keywords: COVID-19, pandemic, cancer management, military hospitals, oncology

Saudi Med J 2021; Vol. 42 (12): 1272-1280
doi: 10.15537/smj.2021.42.12.20210483

From the Department of Oncology, (Al Zahrani, Ghorbel, Mukhtar), King Salman Armed Forces Hospital, Tabuk; from the Department of Oncology, (Almajed, Abdelazim), Prince Sultan Military Medical City, Riyadh; from the Department of Oncology, (Hasan), Al Hada Armed Forces Hospital, Taif; from the Department of Oncology (Mostafa), Armed Forces Hospitals, Khamis Mushait; and from the Department of Oncology, (Al Harbi, Ali Bajouda), King Fahad Armed Forces Hospital, Jeddah, Kingdom of Saudi Arabia.

Received 22nd June 2021. Accepted 5th October 2021.

Address correspondence and reprint request to: Dr. Omar Al Zahrani, Department of Oncology, King Salman Armed Forces Hospital, Tabuk, Kingdom of Saudi Arabia.E-mail: psoc.research@gmail.com ORCID ID: https://orcid.org/0000-0001-7344-1462 
Since the Spanish flu, also known as the 1918 Sinfluenza pandemic, COVID-19 is the second and one of the most deadliest pandemics in history, sharing many similarities. ${ }^{1}$ COVID-19 was first discovered in Wuhan, China, and was rapidly declared a pandemic by the World Health Organization on March 11, 2020. ${ }^{2-4}$ The sudden appearance of COVID-19 and its rapid transmission gave health care systems limited time for adaptation. Since the declaration and in response to the pandemic, health care systems worldwide started to prioritize essential treatment services and protocols. ${ }^{5,6}$ The COVID-19 pandemic significantly affected global health care systems, interrupting services in many health care facilities and exposing vulnerable patients to fatal risks such as increased cancer-related morbidity and mortality due to treatment delays. ${ }^{1,7}$ Moreover, patients with cancer are known to be a fragile population, and the pandemic has made it more challenging by exposing them to life-threatening infections and interruption of cancer or other medical care.

In Saudi Arabia, the first COVID-19 case was confirmed on March 2, 2020. However, the country has experienced cancer management during the Middle East respiratory syndrome coronavirus (MERS-CoV) outbreak. ${ }^{8,9}$ Patients aged $>65$ years and those with other comorbidities such as cancer, immunosuppression, chronic lung disease, and diabetes were known to be at increased risk for mortality when infected with MERS-CoV. ${ }^{8,9}$ Important lessons from their previous experience with MERS-CoV enabled them to focus on the need to ensure continuity of care, minimize harm from acquiring infections, and reduce the number of treatment interruptions. ${ }^{8,10}$ The Saudi Arabia National Cancer Institute provided specific recommendations on cancer patient management according to the infectious status. ${ }^{11}$ To ensure social distancing, the government of Saudi Arabia imposed several anticipatory measures, including lockdowns and curfews. ${ }^{10,12}$ Our study aimed to evaluate the impact of COVID-19 on the quality of cancer management in military hospitals of Saudi Arabia.

Our main objectives were to report and compare 2 of the most essential quality performance indicators of cancer management. The first indicator was the time duration for acceptance of new cancer patients

Disclosure. Authors have no conflict of interests, and the work was not supported or funded by any drug company. in oncology, which was the average time duration between the date of referral and the date of first visit in oncology. This is defined as the sum of the number of days recorded between the date of referral to oncology and the date of first visit in oncology for all patients treated during the above-mentioned periods, divided by the number of patients treated. The second indicator was the time duration to initiate oncology treatment; the average time duration between the date of cancer diagnosis and the date of the first oncology treatment (surgery, radiotherapy, or systemic treatment). This is defined as the sum of the number of days recorded between the date of cancer diagnosis and the date of cancer treatment initiation for all patients treated during the above-mentioned periods, divided by the number of patients treated. ${ }^{13,14}$

Methods. We conducted a multi-centric, record based, retrospective, comparative study of 2 groups of adult cancer patients treated in all military hospitals in Saudi Arabia, providing oncology services from February to July 2019 and 2020. An ethical approval was obtained from Central Research Ethics Committee, Medical Services General Directorate (MSD). We collected data from Prince Sultan Military Medical City (PSMMC), Riyadh, considered as a reference center; King Fahad Armed Forces Hospital (KFAFH), Jeddah; King Salman Armed Forces Hospital (KSAFH), Tabuk; Al Hada Armed Forces Hospital (AL HADA), Taif; and Armed Forces Hospital Southern Region (AFHSR), Khamis Mushait.

Our target population consisted of 2 groups. Group A represented all adult cancer patients treated from February to July 2019. Group B consisted of cancer patients treated from February to July 2020. Information regarding patients' date of diagnosis, date of the first visit to the oncology clinic, and treatment plan, along with their demographic variables, were collected. The eligibility status was defined as military, military dependents, or armed forces medical services directorate civilian staff, and the referral way to oncology was from the same hospital, another military hospital, or ministry of health hospital. We reported other parameters that reflected the magnitude of services during this period. The number of newly diagnosed cancer cases (number of newly diagnosed/accepted cases during these periods), the number of eligible cases versus (vs.) the number of non-eligible cases, and the number of patients referred from other hospitals (other military hospitals or ministry of health hospital).

We presented the clinical data regarding COVID-19-positive active cancer patients (clinical 
presentation, manifestation, management, and possible complications). We conducted a retrospective evaluation of the outcomes and survival of these patients (active, recovery, hospitalized but not in the intensive care unit [ICU]; hospitalized in ICU; placed on a ventilator; and death), including cancer outcomes (stable, response to treatment, progression, delayed treatment, discontinued treatment, and death).

We followed the criteria for recovery of the COVID-19 Guidelines v1.2 published in March 2020 by the Saudi Center for Disease Prevention and Control and the Ministry of Health. ${ }^{15}$ It consisted of 2 negative RT-PCR tests, 24 hours apart. All patients treated for malignancy in military hospital, patients who received active treatment (surgery, systemic treatment and radiotherapy) were included in the study. While the exclusion criteria were patients diagnosed with malignancy but not receiving active treatment such as palliative cases and patient diagnosed with malignancy but not treated in military hospitals.

Statistical analysis. Data were gathered and entered into SPSS for Windows, version 20 (IBM Corp., Armonk, N.Y., USA). The descriptive analysis of the demographic characteristics of the patients was presented in Table 1 . Normality of the data was analyzed by Kolmogorov-Smirnov test. Mann-Whitney U-test was used to determine any difference between the time duration of acceptance of cancer cases and the start of treatment in 2019 and 2020, as the data sets were not normally distributed. Chi-square and Fisher exact test was used to determine any association between the number of cases, their eligibility, and referral status in 2019 and 2020. A $p$-value of $<0.05$ was considered statistically significant.

Detailed information regarding the COVID-19positive cancer patients, such as diagnosis, symptomatic status, outcomes, and progression of the disease, were analyzed (cross-sectional analysis) and the results were presented in a tabulated form.

Results. Data of 1574 cancer patients were collected, which included military hospitals. The total number of patients in 2019 was 856 and 718 in 2020, of which females were in majority with $55.6 \%$ in 2019 and $55.2 \%$ in 2020 ( $p=0.857)$. The mean age of the sample of 2020 was reported slighter higher than 2019 ( $p=0.601)$ (Table 1).

Regarding the referral activities in this study, there was reported a significant reduction in the total number of referred cases in the sample of 2020, from another department within a military hospital and from one military hospital to another. However, the number of referred cases from civilian hospitals were accepted doubled in 2020 from 62 to 121 cases $(p=0.00)$ (Table 1 ). As the consequences of increase in referred cases from civilian hospital, the eligibility status of non-military patients were significantly increased in 2020. Table 1 illustrates the comparative analysis of all demographic features between 2 samples (2019 and 2020).

Furthermore, breast cancer was the most common type of cancer, followed by colorectal cancer in both sample groups (2019 and 2020). However, corpus uteri cancer ranked 3rd among the sample of 2020 instead of thyroid cancer in 2019. Table 2 shows the comparative

Table 1 - Comparative analysis of demographic features between 2 samples (2019 and 2020).

\begin{tabular}{lcccccc}
\hline $\begin{array}{l}\text { Demographic } \\
\text { characteristic }\end{array}$ & $\mathbf{n}$ & $(\%)$ & $\mathbf{n}$ & $(\%)$ & $\begin{array}{c}\text { Chi square/ } \\
\text { Fisher statistics }\end{array}$ & $P$-value \\
\hline $\begin{array}{l}\text { Gender, } n \text { (\%) } \\
\text { Male }\end{array}$ & 380 & $(44.4)$ & 322 & $(44.8)$ & & \\
$\quad \begin{array}{l}\text { Female } \\
\text { Eligibility, } n \text { (\%) }\end{array}$ & 476 & $(55.6)$ & 396 & $(55.2)$ & 0.033 & 0.857 \\
$\begin{array}{l}\text { Military } \\
\text { Non-military }\end{array}$ & 787 & $(92.8)$ & 636 & $(89.0)$ & & \\
$\begin{array}{l}\text { Referred hospital, } n(\%) \\
\text { Same }\end{array}$ & 61 & $(7.2)$ & 79 & $(11.0)$ & & 0.008 \\
Other military & 705 & $(84.5)$ & 534 & $(76.2)$ & & \\
Other civilian & 67 & $(8.0)$ & 46 & $(6.6)$ & 35.266 & 0.000 \\
& 62 & $(7.4)$ & 121 & $(17.3)$ & & \\
Age & Mean \pm SD & Range & Mean \pm SD & Range & T-statistics & $P$-value \\
\hline
\end{tabular}

Total of some categories do not add to the total sample size such as "1574" due to some "missing data" in these categories. SD: standard deviation 
Table 2 - Comparison between the 2 samples (2019 and 2020) in terms of cancer sites.

\begin{tabular}{|c|c|c|c|c|c|c|}
\hline \multirow[t]{2}{*}{ Cancer type } & \multicolumn{2}{|c|}{2019} & \multicolumn{2}{|c|}{2020} & \multicolumn{2}{|c|}{ Total } \\
\hline & $\mathbf{n}$ & $\%$ & $\mathbf{n}$ & $\%$ & $\mathrm{n}$ & $\%$ \\
\hline Breast & 156 & 18.3 & 141 & 19.7 & 297 & 19.0 \\
\hline Colorectal & 130 & 15.3 & 124 & 17.4 & 254 & 16.2 \\
\hline Thyroid & 85 & 10.0 & 25 & 3.5 & 110 & 7.0 \\
\hline NHL & 55 & 6.5 & 39 & 5.5 & 94 & 6.0 \\
\hline Corpus uteri & 41 & 4.8 & 46 & 6.4 & 87 & 5.6 \\
\hline Prostate & 49 & 5.8 & 25 & 3.5 & 74 & 4.7 \\
\hline Head and neck & 27 & 3.2 & 39 & 5.5 & 66 & 4.2 \\
\hline Lungs & 31 & 3.6 & 28 & 3.9 & 59 & 3.8 \\
\hline Gastric & 22 & 2.6 & 29 & 4.1 & 51 & 3.3 \\
\hline Pancreas & 24 & 2.8 & 26 & 3.6 & 50 & 3.2 \\
\hline Brain & 21 & 2.5 & 26 & 3.6 & 47 & 3.0 \\
\hline Kidney & 28 & 3.3 & 13 & 1.8 & 41 & 2.6 \\
\hline Ovary & 21 & 2.5 & 15 & 2.1 & 36 & 2.3 \\
\hline Skin & 21 & 2.5 & 14 & 2.0 & 35 & 2.2 \\
\hline Liver & 16 & 1.9 & 14 & 2.0 & 30 & 1.9 \\
\hline Soft tissue & 17 & 2.0 & 13 & 1.8 & 30 & 1.9 \\
\hline Bladder & 12 & 1.4 & 16 & 2.2 & 28 & 1.8 \\
\hline $\begin{array}{l}\text { Hodgkin } \\
\text { lymphoma }\end{array}$ & 12 & 1.4 & 6 & 0.8 & 18 & 1.1 \\
\hline Testicular & 11 & 1.3 & 6 & 0.8 & 17 & 1.1 \\
\hline Leukemia & 7 & 0.8 & 8 & 1.1 & 15 & 1.0 \\
\hline Esophagus & 5 & 0.6 & 8 & 1.1 & 13 & 0.8 \\
\hline Bones & 6 & 0.7 & 6 & 0.8 & 12 & 0.8 \\
\hline Multiple myeloma & 5 & 0.6 & 4 & 0.6 & 9 & 0.6 \\
\hline $\begin{array}{l}\text { Myeloproliferative } \\
\text { neoplasm }\end{array}$ & 2 & 0.2 & 6 & 0.8 & 8 & 0.5 \\
\hline $\begin{array}{l}\text { Malignancy of } \\
\text { unknown origin }\end{array}$ & 5 & 0.6 & 3 & 0.4 & 8 & 0.5 \\
\hline Tongue & 1 & 0.1 & 6 & 0.8 & 7 & 0.4 \\
\hline Others & 42 & 4.9 & 28 & 3.9 & 70 & 4.5 \\
\hline Total & 852 & 100 & 714 & 100 & 1566 & 100 \\
\hline
\end{tabular}

Due to some missing information (data) of the diagnosis of the some malignant cases the totals do not add to the sample size.

analysis of different cancer sites between 2 samples (2019-2020).

Concerning time duration for acceptance of new cancer patients in oncology (all hospitals included), the mean time was 7.3 days in 2019 and 8 days in 2020, respectively, with no statistically significant difference $(p=0.194)$. Similarly, in terms of time duration for oncology treatment initiation, no statistically significant difference was reported between 2019 (mean as 38.4 days) and 2020 (mean as 44.3 days) ( $p=0643$ )(Table 3).

Results by hospital. The highest number of patients was reported in PSMMC (601 patients, 365 in 2019 and 236 in 2020), and the lowest was in AFHSR (179 patients, 82 in 2019 and 97 in 2020) (Table 4).
In terms of referral status, we observed a statistically significant reduction in the number of patients referred to PSMMC from other military hospitals $(p=0.01)$. The number of non-military patients also decreased in 2020 for the same hospital. The reduction, however, was not statistically significant $(p=0.15)$.

In KSAFH, the number of patients referred from other hospitals (military and civilian) increased significantly in $2020(p=0.00)$, as well as the number of non-eligible cases $(p=0.00)$. This was the most important change in activities in KSAFH.

In AL HADA, the trend of change in referral status and acceptance of non-eligible cases was similar to Tabuk hospital. However, there was no statistically significant difference $(p>0.05)$.

For other military hospitals, the referral status and acceptance of non-eligible cases did not change significantly between the 2 periods (Table 4) The time duration for acceptance of new cancer patients in oncology did not change significantly between 2019 and 2020 , in 3 of the 5 hospitals. This duration increased significantly in KFAFH (mean rank 102.44 and 120.64, $p=0.02$ ) and AL HADA (mean rank 97.22 and 119.52, $p=0.00$ ). In addition, we found no significant difference in the time duration for oncology treatment initiation for all military hospitals. Detailed results of individual hospitals are presented in Table 3.

Oncology results of COVID-19-positive patients. Overall, we collected data of 76 COVID-19-positive cancer patients ( 28 males, 48 females) between February and July 2020 from all the military hospitals. Riyadh reported the highest number of COVID-19 patients (38 cases, 50\%). Most of the patients in our study were found symptomatic (71.6\%), with fever as the common symptom $(58.5 \%)$, followed by cough $(49.1 \%)$ and shortness of breath (26.4\%). In these patients, breast cancer was the most common type of cancer $(32.9 \%)$, followed by colorectal (21.1\%), and non-Hodgkin lymphoma (7.9\%).

Furthermore, $72.4 \%$ of the patients recovered from COVID-19, 22.3\% (17 cases) died due to COVID-19 complications, and 8\% (6 cases) died due to cancer (after recovery from COVID-19). We noted 3 admissions in the ICU needing mechanical ventilation and eventually died. Cancer progression was reported in 7 patients, of which 2 died and one discontinued the treatment and eventually died. However, $58 \%$ of the cases were controlled from an oncological point of view. Table 5 summarizes the data regarding COVID-19 cases.

Discussion. The number of cancer patients in military hospitals decreased from 856 in 2019 to 718 
COVID-19 impact on oncology services... Al Zahrani et al

Table 3 - Comparison between the 2 samples (2019 and 2020) in time duration for acceptance and start of first oncology treatment.

\begin{tabular}{|c|c|c|c|c|c|c|c|}
\hline Hospitals & KPIs & Year & n & Mean \pm SD & Median & z-scores & $P$-value \\
\hline \multirow{4}{*}{$\begin{array}{l}\text { Overall } \\
\text { combined }\end{array}$} & \multirow{2}{*}{$\begin{array}{l}\text { Time duration for acceptance of new cancer } \\
\text { patient in oncology }\end{array}$} & 2019 & 736 & $7.3 \pm 27.8$ & 5.0 & \multirow{2}{*}{-1.299} & \multirow{2}{*}{0.194} \\
\hline & & 2020 & 635 & $8.0 \pm 25.4$ & 4.0 & & \\
\hline & \multirow{2}{*}{$\begin{array}{l}\text { Time duration to start first oncological } \\
\text { treatment }\end{array}$} & 2019 & 686 & $38.4 \pm 48.1$ & 26.0 & \multirow{2}{*}{-0.464} & \multirow{2}{*}{0.643} \\
\hline & & 2020 & 574 & $44.3 \pm 67.9$ & 25.0 & & \\
\hline \multirow[t]{4}{*}{ KFAFH Jeddah } & \multirow{2}{*}{$\begin{array}{l}\text { Time duration for acceptance of new cancer } \\
\text { patient in oncology }\end{array}$} & 2019 & 128 & $8.4 \pm 35.9$ & 0.0 & \multirow{2}{*}{-2.363} & \multirow{2}{*}{0.018} \\
\hline & & 2020 & 91 & $16.2 \pm 58.5$ & 1.0 & & \\
\hline & \multirow{2}{*}{$\begin{array}{l}\text { Time duration to start first oncological } \\
\text { treatment }\end{array}$} & 2019 & 154 & $22.6 \pm 40.2$ & 11.0 & \multirow{2}{*}{-1.568} & \multirow{2}{*}{0.117} \\
\hline & & 2020 & 93 & $37.6 \pm 73.8$ & 14.0 & & \\
\hline \multirow[t]{4}{*}{ KSAFH Tabuk } & \multirow{2}{*}{$\begin{array}{l}\text { Time duration for acceptance of new cancer } \\
\text { patient in oncology }\end{array}$} & 2019 & 91 & $9.0 \pm 38.9$ & 3.0 & \multirow{2}{*}{-0.741} & \multirow{2}{*}{0.459} \\
\hline & & 2020 & 126 & $5.2 \pm 7.2$ & 3.0 & & \\
\hline & \multirow{2}{*}{$\begin{array}{l}\text { Time duration to start first oncological } \\
\text { treatment }\end{array}$} & 2019 & 89 & $20.2 \pm 19.3$ & 17.0 & \multirow{2}{*}{-0.780} & \multirow{2}{*}{0.435} \\
\hline & & 2020 & 115 & $17.8 \pm 18.0$ & 14.0 & & \\
\hline \multirow[t]{4}{*}{ PSMMC Riyadh } & \multirow{2}{*}{$\begin{array}{l}\text { Time duration for acceptance of new cancer } \\
\text { patient in oncology }\end{array}$} & 2019 & 361 & $8.1 \pm 22.9$ & 7.0 & \multirow{2}{*}{-1.345} & \multirow{2}{*}{0.179} \\
\hline & & 2020 & 235 & $8.9 \pm 10.7$ & 6.0 & & \\
\hline & \multirow{2}{*}{$\begin{array}{l}\text { Time duration to start first oncological } \\
\text { treatment }\end{array}$} & 2019 & 343 & $44.1 \pm 51.0$ & 30.0 & \multirow{2}{*}{-0.087} & \multirow{2}{*}{0.931} \\
\hline & & 2020 & 229 & $39.3 \pm 59.5$ & 32.0 & & \\
\hline \multirow{4}{*}{$\begin{array}{l}\text { AFHSR Khamis } \\
\text { Mushait }\end{array}$} & \multirow{2}{*}{$\begin{array}{l}\text { Time duration for acceptance of new cancer } \\
\text { patient in oncology }\end{array}$} & 2019 & 58 & $4.4 \pm 4.4$ & 2.5 & \multirow{2}{*}{-0.244} & \multirow{2}{*}{0.807} \\
\hline & & 2020 & 63 & $5.0 \pm 6.7$ & 2.0 & & \\
\hline & \multirow{2}{*}{$\begin{array}{l}\text { Time duration to start first oncological } \\
\text { treatment }\end{array}$} & 2019 & 23 & $11.4 \pm 22.0$ & 1.0 & -0.064 & 0.949 \\
\hline & & 2020 & 32 & $11.9 \pm 19.6$ & 0.0 & & \\
\hline AL HADA Taif & Time duration for acceptance of new cancer & 2019 & 98 & $2.2 \pm 10.9$ & 0.0 & -2.998 & 0.003 \\
\hline & ent in oncology & 2020 & 120 & $1.6 \pm 2.5$ & 0.0 & & \\
\hline & Time duration to start first oncological & 2019 & 77 & $57.7 \pm 65.1$ & 35.0 & -1.166 & 0.243 \\
\hline & tre & 2020 & 105 & $73.2 \pm 82.6$ & 42.0 & & \\
\hline
\end{tabular}

KFAFH: King Fahad Armed Forces Hospital, KSAFH: King Salman Armed Forces Hospital, PSMMC: Prince Sultan Military Medical City, AL HADA: Al Hada Armed Forces Hospital, AFHSR: Armed Forces Hospital Southern Region, SD: standard deviation, KPI: key performance indicator

Table 4 - Comparison between the 2 samples (2019 and 2020) in terms of referral activities among different hospitals.

\begin{tabular}{|c|c|c|c|c|c|c|c|c|}
\hline \multirow[b]{2}{*}{ Hospitals } & \multirow[b]{2}{*}{ Year } & \multicolumn{4}{|c|}{ Referral status } & \multicolumn{3}{|c|}{ Eligibility status } \\
\hline & & $\begin{array}{c}\text { Same } \\
\text { hospital }\end{array}$ & $\begin{array}{l}\text { Other } \\
\text { military }\end{array}$ & $\begin{array}{l}\text { Other } \\
\text { civilian }\end{array}$ & $P$-value & Military & $\begin{array}{c}\text { Non } \\
\text { military }\end{array}$ & $P$-value \\
\hline \multirow[t]{2}{*}{ KFAFH Jeddah } & 2019 & 191 & 3 & 6 & \multirow{2}{*}{0.23} & 192 & 2 & \multirow{2}{*}{0.86} \\
\hline & 2020 & 108 & 3 & 8 & & 119 & 1 & \\
\hline \multirow[t]{2}{*}{ KSAFH Tabuk } & 2019 & 89 & 2 & 6 & \multirow{2}{*}{0.00} & 101 & 9 & \multirow{2}{*}{0.00} \\
\hline & 2020 & 91 & 6 & 35 & & 113 & 30 & \\
\hline \multirow[t]{2}{*}{ PSMMC Riyadh } & 2019 & 286 & 55 & 15 & \multirow{2}{*}{0.01} & 345 & 20 & \multirow{2}{*}{0.15} \\
\hline & 2020 & 183 & 26 & 24 & & 228 & 7 & \\
\hline \multirow{2}{*}{$\begin{array}{l}\text { AFHSR Khamis } \\
\text { Mushait }\end{array}$} & 2019 & 75 & 1 & 6 & \multirow{2}{*}{0.45} & 77 & 3 & \multirow{2}{*}{0.89} \\
\hline & 2020 & 92 & 0 & 5 & & 93 & 4 & \\
\hline \multirow[t]{2}{*}{ AL HADA Taif } & 2019 & 64 & 6 & 29 & \multirow{2}{*}{0.09} & 72 & 27 & \multirow{2}{*}{0.56} \\
\hline & 2020 & 60 & 11 & 49 & & 83 & 37 & \\
\hline $\begin{array}{l}\text { Total of the var } \\
\text { Armed For }\end{array}$ & $\begin{array}{l}\text { are no } \\
\text { spital, }\end{array}$ & $\begin{array}{l}\text { to the t } \\
\text { H: King } \\
\text { la Armec }\end{array}$ & $\begin{array}{l}\text { aple size } \\
\text { Armed I } \\
\text { Hospital }\end{array}$ & some "m & $\begin{array}{l}\text { data" in } \\
\text { MC: } \mathrm{Pr} \\
\text { rces Ho }\end{array}$ & $\begin{array}{l}\text { e variabl } \\
\text { Sultan } N \\
\text { I Souther }\end{array}$ & $\begin{array}{l}\text { FAFH: K } \\
\text { ary Medica } \\
\text { egion }\end{array}$ & $\begin{array}{l}\text { g Fahad } \\
\text { City, }\end{array}$ \\
\hline
\end{tabular}


Table 5 - Characteristics of COVID positive patients.

\begin{tabular}{|c|c|c|}
\hline Characteristics & $\mathrm{n}$ & $\%$ \\
\hline \multicolumn{3}{|l|}{ Number of cases by hospital } \\
\hline KFAFH Jeddah & 11 & 14.5 \\
\hline KSAFH Tabuk & 12 & 15.8 \\
\hline PSMMC Riyadh & 38 & 50.0 \\
\hline AFHSR Khamis Mushait & 2 & 2.6 \\
\hline AL HADA Taif & 13 & 17.1 \\
\hline \multicolumn{3}{|l|}{ Gender } \\
\hline Male & 28 & 36.8 \\
\hline Female & 48 & 63.2 \\
\hline \multicolumn{3}{|l|}{ Symptomatic } \\
\hline Yes & 55 & 71.6 \\
\hline No & 21 & 28.4 \\
\hline \multicolumn{3}{|l|}{${ }^{*}$ Common symptoms } \\
\hline Fever & 31 & 58.5 \\
\hline Cough & 26 & 49.1 \\
\hline Shortness of breath & 14 & 26.4 \\
\hline Diarrhea & 5 & 9.4 \\
\hline \multicolumn{3}{|l|}{ Outcome of Covid-19 } \\
\hline Active & 1 & 1.3 \\
\hline Recovered & 55 & 72.4 \\
\hline Hospitalized (in ICU on ventilator) & 3 & 3.9 \\
\hline Expired due to Covid-19 & 17 & 22.4 \\
\hline \multicolumn{3}{|l|}{ Cancer outcome } \\
\hline Stable & 23 & 30.3 \\
\hline Response to treatment & 21 & 27.6 \\
\hline Progression & 7 & 9.2 \\
\hline Treatment discontinued & 1 & 1.3 \\
\hline Overall expired cases & 23 & 30.3 \\
\hline \multicolumn{3}{|c|}{$\begin{array}{l}\text { *Common symptoms are not mutually exclusive. Total of the some } \\
\text { variables are not equal to the total sample size due to some "missing data" } \\
\text { in these variables. KFAFH: King Fahad Armed Forces Hospital, KSAFH } \\
\text { King Salman Armed Forces Hospital, PSMMC: Prince Sultan Military } \\
\text { Medical City, AL HADA: Al Hada Armed Forces Hospital, AFHSR: } \\
\text { Armed Forces Hospital Southern Region, ICU: intensive care unit }\end{array}$} \\
\hline
\end{tabular}

in 2020, attributed to a multifactorial effect. Firstly, reduction in referrals from other services (limitations of diagnostic activities), and secondly, patients delayed hospital visits due to fear of getting infected with COVID-19 during these visits. However, the number of newly diagnosed cancer patients in peripheral military hospitals increased during this period in 2020 as compared to the same period in 2019. In
AFHSR, the number of newly diagnosed cancer cases increased within the same hospital. In KSAFH and AL HADA, the number of referred cases (from another military or Ministry of Health hospital) increased, while the number of in-hospital cases was stable. On the contrary, military hospitals in Riyadh and Jeddah noted reductions in newly diagnosed cancer cases. For PSMMC, the change in number was related to the reduction of in-hospital cases and the number of referrals from peripheral hospitals due to restrictions, such as lockdown and curfew, implemented during this period. This forced many patients to consult the nearest hospital. With regard to KFAFH, the reduction of the number of cases in 2020 was attributed to the decreased newly diagnosed cases in the same hospital due to COVID-19 related restriction of care. ${ }^{16}$

In terms of non-eligible cases, the numbers increased in some peripheral hospitals compared to the referral centers. The lockdown and movement limitations enforced patients to conduct or continue their oncological treatments in the nearest centers. Some of these patients were newly diagnosed in a peripheral Ministry of Health hospital, whereas others were on active cancer treatment in a reference Ministry of Health cancer center. Nonetheless, a collaboration between the Ministry of Health hospitals and military hospitals enabled adequate and timely management of cancer patients.

In the military hospitals, no statistically significant difference in terms of acceptance of cancer patients was noted between 2020 and 2019. This duration increased significantly in KFAFH $(p=0.02)$. However, the mean time for acceptance matched the international benchmarks. ${ }^{17}$ In AL HADA hospital, there was a significant change in duration for acceptance $(p=0.000)$, with a mean of 2.18 and 1.65 days, respectively. In this hospital, most of the newly diagnosed cancer patients were consulted by oncologists on the same day of referral (first visit).

No statistically significant difference was observed in the time duration for oncology treatment initiation in all military hospitals, which was attributed to the fact oncology is considered a priority care. Continuity of oncological treatments during the COVID-19 period and adapting to the treatment protocols as per the new guidelines was crucial.

According to the information we have, there are limited studies investigating cancer management in Saudi Arabia's military hospitals. Jaziahet $\mathrm{al}^{18}$ conducted a cross-sectional study including 356 centers from 54 countries between April 21 and May 8, 2020. The study reported that $88.2 \%$ of the centers experienced 
different challenges in cancer management,including services reduction by $55.3 \%$, and $46.2 \%$ of the centers reported missing at least one cycle of therapy in $10 \%$ of patients. These were attributed to the overwhelmed healthcare system (19.9\%), lack of personal protective equipment $(19.1 \%)$, staff shortages $(18 \%)$, and restricted access to medications (9.8\%). Furthermore, Maringe et $\mathrm{al}^{19}$ conducted a national population-based modeling study in the United Kingdom to estimate the impact of the COVID-19 pandemic on cancer deaths due to delays in diagnosis. The study included 32583 breast cancer, 24975 colorectal cancer, 6744 esophageal cancer, and 29305 lung cancer patients. Compared to the pre-pandemic period, there was a 7.9\%-9.6\% increase in the number of deaths due to breast cancer, $15.3 \%-16.6 \%$ for colorectal cancer, and $4.8 \%-5.3 \%$ for lung cancer. The first COVID-19-oncology experience was reported from Italy by Zulianiet al. ${ }^{20}$ They recorded data regarding oncological activities in Verona, Italy, from January 1 to March 31, 2020, vs. the same period of 2019, as well as other data. As compared with the same trimester in 2019, there was a reduction in total numbers of admissions, chemotherapy administrations, and specialist visits from January to March 2020 (8\%, $6 \%$, and $3 \%$ reduction, respectively). The authors noted a slight but statistically significant reduction in oncology activity during the epidemic peak.

Regarding patient's perspectives on oncological care during the COVID-19 pandemic, De Joode et al ${ }^{21}$ conducted a survey among 5302 cancer patients in the Netherlands between March and April 2020, using an online survey. Overall, $30 \%$ of the patients experienced some challenges during their oncological treatment or follow-up. Chemotherapy (30\%) and immunotherapy (32\%) were the most frequently adjusted treatments. More than $55 \%$ of patients were concerned regarding the discontinuation or delay of their cancer management. Patients in regions with high COVID-19 incidence were significantly more concerned. Tashkandi et $\mathrm{al}^{22}$ studied other feedbacks from Saudi patients. They conducted a self-administered electronic survey among cancer patients, aiming to determine the impact of the COVID-19 pandemic on cancer patients and their perceptions. Twenty-two percent of patients reported that their cancer care was affected. Sixty-one percent of the population convinced that cancer patients were more susceptible to COVID-19 infection.

Manifestly, there is a clear difference between our results and the literature, despite our different methodologies. We justified this considering the difference between military and other healthcare systems, in terms of patient load (selected and lesser eligible population for military medical services), presence of a fully trained military medical staff, and presence of expert leaders to respond to various types of disasters, which permitted a rapid and comprehensive services adaptation to the new situation. From a methodology standpoint and to our knowledge, our study is the first to determine the impact of COVID-19 on cancer management using objective parameters rather than questionnaires.

Data of 76 cases were collected from all military hospitals. Most of the patients developed symptoms (71.6\%), essentially fever. A significant difference in terms of COVID-19 cases between Riyadh military hospital and other hospitals was noted; this was due to the difference in COVID-19 incidence between Riyadh and other cities. Remarkably, cancer complications were found to be the cause of death in 6 of the 23 patients who died rather instead of due to COVID-19 infections, as they recovered from COVID-19 prior to death. This limited number of infections among cancer patients was related to infection precaution education given routinely to these patients and the role of infection control and health staff in military hospitals. Wearing masks and frequent hand washing has always been the routine for cancer patients even prior to the COVID-19 era.

The mortality rate was high among our population $(22.3 \%)$ and was comparable to the literature. El Gohary et $\mathrm{al}^{23}$ performed a systematic review and meta-analysis to evaluate the impact of COVID-19 infection on cancer patients. They reported a $21.1 \%$ mortality rate, $45.4 \%$ severe/critical disease rate, $14.5 \%$ ICU admission rate, and $11.7 \%$ mechanical ventilation rate. This susceptibility of cancer patients to COVID-19 has been confirmed in many studies. ${ }^{24-26}$ Salunke et $\mathrm{al}^{24}$ conducted a systematic review and meta-analysis on 3775 patients of whom 63 (1.7\%) had cancer. They found the percentage of ICU admission in COVID-19 patients with and without cancer of $40 \%$ vs. $8.4 \%$. The pooled estimates of the death rate in COVID-19 patients with and without cancer were $20.83 \%$ vs. $7.82 \%$. To determine predictive factors for poor outcomes in terms of severe respiratory distress (acute respiratory distress syndrome [ARDS]) or death, Yarza et $\mathrm{a}^{25}$ did a retrospective statistical analysis to describe the characteristics of the disease in 63 cancer patients. Thirty-four of them developed respiratory failure (70\% as ARDS). The mortality rate was $25 \%$, significantly higher among ARDS, neutropenic patients $(p=0.01)$, and in those with bilateral infiltrates. This worse outcome for COVID-19 infected cancer patients noted by Kuderer et $\mathrm{a}^{26}$ in their cohort study. The 
authors found 121 (13\%) deaths among 928 patients with active or previous malignancy and confirmed COVID-19-related severe acute respiratory syndrome.

The susceptibility of cancer patients to COVID-19 complications encouraged oncologists to modify their practice. This was reported by Urun et $\mathrm{a}^{127}$ in their online survey that included 343 oncologists from 28 countries. Hormonal therapy and tyrosine kinase inhibitors were considered safe, where as cytotoxic chemotherapy and immune therapies were found to be risky. The majority of the participants were in favor of using less chemotherapy, immune checkpoint inhibitors, and steroids. Treatment in neo-adjuvant, adjuvant, and first-line metastatic disease was less effective. However, most of the participants were not encouraged to recommend second- or third-line therapies in metastatic disease. On the contrary, Angelis et $\mathrm{al}^{28}$ conducted a prospective epidemiological and clinical data collection of approximately 13,489 cancer patients between March 1 and April 30, 2020. Among this population, $0.84 \%$ were swab positive, $0.75 \%$ required hospital admission, and $0.21 \%$ died of COVID-19. Of the patients that attended the hospital to receive cytotoxic chemotherapy alone or together with other therapy, $2.9 \%$ admitted to the hospital for COVID-19 related issues and $0.21 \%$ died. Of the patients who visited for targeted treatments, $1.4 \%$ were admitted and $0.1 \%$ died. Of the 11 patients that had received radiotherapy, $0.6 \%$ required inpatient admission and $0.2 \%$ died. The authors concluded that systemic anticancer therapy appears to be associated with a modest risk of severe COVID-19 infection, and the continuation of active cancer treatment is appropriate.

Study limitations. This a multi-centric retrospective descriptive study including regional and referral centers, so there are some discrepancies in the data due to different set-ups and adopted procedures in terms of acceptance and treatment of oncological cases. In addition, the study did not focus on delay of diagnosis and its impact on cancer staging and treatment. Diagnosis is beyond oncology services.

In conclusion, cancer management in Saudi Arabia's military hospitals was not significantly affected during the first 6 months of the COVID-19 pandemic. However, it affected the early diagnosis of cancer patients in some hospitals due to limited diagnostic services available at the time and the delay of care by patients themselves due to fear of COVID-19 infection. Nonetheless, the collaboration between different military hospitals and Ministry of Health hospitals ensured continuous oncological care despite the increasing number of COVID-19 cases. If infected, cancer patients are at an increased risk for COVID-19 complications, including death. More follow-ups and further research is warranted to determine the real impact of COVID-19 on patients with cancer.

Acknowledgment. We gratefully appreciation the Ministry of Defence authorities for their valuable and constructive suggestions and approval for this multi-centre research. We are very grateful to all data collection staff of the participated centres. Lastly, we would like to thank Scribendi (www.scribendi.com) for the English language editing.

\section{References}

1. Guan WJ, Ni ZY, Hu Y, Liang WH, Ou CQ, He JX, et al. Clinical characteristics of coronavirus disease 2019 in China. $N$ Engl J Med 2020; 382: 1708-1720.

2. World Health Organization. Coronavirus disease (COVID-19) outbreak. [Updated 2020; Accessed 2021 May 10]. Available from: https://www.who.int/emergencies/disease-outbreak-news

3. World Health Organization. Coronavirus disease (COVID2019) situation reports. [Updated 2020; 2021 May 10]. Available from: https://www.who.int/emergencies/diseases/ novel-coronavirus-2019/situation-reports

4. Simcock R, Thomas TV, Estes C, Filippi AR, Katz MS, Pereira IJ, et al. COVID-19: Global radiation oncology's targeted response for pandemic preparedness. Clin Transl Radiat Oncol 2020; 22: 55-68.

5. Raymond E, Thieblemont C, Alran S, Faivre S. Impact of the COVID-19 Outbreak on the management of patients with Target Oncol 2020; 15:249-259.

6. Khare SR, Batist G, Bartlett G. Identification of performance indicators across a network of clinical cancer programs. Curr Oncol 2016; 23: 81-90.

7. van de Haar J, Hoes LR, Coles CE, Seamon K, Fröhling S, Jäger $\mathrm{D}$, et all. Caring for patients with cancer in the COVID-19 era. Nat Med 2020; 26: 665-671.

8. Jazieh AR, Al Hadab A, Al Olayan A, AlHejazi A, Al Safi F, Al Qarni A, et al. (2020) Managing oncology services during a major coronavirus outbreak: lessons from the Saudi Arabia experience. JCO Glob Oncol 2020; 6: GO.20.00063.

9. Memish ZA, Perlman S, Van Kerkhove MD. Middle East respiratory syndrome. Lancet 2020; 395: 1063-1077.

10. Alessy SA, Davies EA, Jazieh AR. Cancer care during the COVID-19 pandemic: a perspective from Saudi Arabia. Ecancer 2020; 14: 1076.

11. Ministry of Health. Saudi Arabia National Cancer Institute (2020) Coronavirus Disease 2019 ( COVID-19). Caregiver and Facility Clinical Practice Guidelines. [Updated 2020; Accessed 2021 February 15]. Available from: https://www.moh. gov.sa/Ministry/MediaCenter/Publications/Documents/SaudiArabia-National-Cancer.pdf

12. Algaissi AA, Alharbi NK, and Hassanain M, Hashem A. Preparedness and response to COVID-19 in Saudi Arabia: building on MERS experience. J Infect Public Health 2020; 13 : 834-838.

13. Neuss M, Rocque G, Zuckerman D, Chiang A, Katta S, Wollins $\mathrm{D}$, et al. Establishing a core set of performance measures to improve value in cancer care: ASCO consensus conference recommendation report. J Oncol Pract 2017; 13: 135-140. 
14. Ministry of Health. Coronavirus Disease COVID-19 Guidelines v1.2. [Updated 2020 March: Accessed 2021 February 15]. Available from: https://covid19.cdc.gov.sa/ wp-content/uploads/2020/03/Coronavirus-Disease-2019Guidelines-v1.2.pdf.pdf

15. Franchini AF, Auxilia F, Galimberti PM, Piga MA, Castaldi S, Porro A. COVID 19 and Spanish flu pandemics: All it changes, nothing changes. Acta Biomed 2020; 91: 245-250.

16. Alyami MH, Naser AY, Orabi MAA, Alwafi H, Alyami HS. Epidemiology of COVID-19 in the Kingdom of Saudi Arabia: an ecological study. Front Public Health 2020; 8: 506.

17. National Health Service. Waiting Times for Suspected and Diagnosed Cancer Patients. 2016-2017 Annual Report. [Updated 2017; Accessed 2021 February 18 Available from: https:/www.england.nhs.uk/statistics/wp-content/ uploads/sites/2/2017/06/Cancer-Waiting-Times-AnnualReport-201617-1.pdf

18. Jazieh AR, Akbulut H, Curigliano G, Rogado A, Alsharm AA, Razis ED, et al. Impact of the COVID-19 pandemic on cancer care: A global collaborative study. JCO Global Oncol 6: $1428-1438$.

19. 19. Maringe C, Spicer J, Morris M, Purushotham A, Nolte E, Sullivan R, et al. The impact of the COVID-19 pandemic on cancer deaths due to delays in diagnosis in England, UK: a national, population-based, modelling study. Lancet Oncol 2020; 21: 1023-1034.

20. Zuliani S, Zampiva I, Tregnago D, Casali M, Cavaliere A, Fumagalli A, et al. Organisational challenges, volumes of oncological activity and patients' perception during the severe acute respiratory syndrome coronavirus 2 epidemic. Eur J Cancer 2020; 135: 159-169.

21. De Joode K, Dumoulin DW, Engelen V, Bloemendal HJ, Verheij $M$, van Laarhoven HW, et al. Impact of the coronavirus disease 2019 pandemic on cancer treatment: the patients' perspective. Eur J Cancer 2020 132-139.
22. Tashkandi E, BaAbdullah M, Zeeneldin A, AlAbdulwahab A, Elemam O, Elsamany $S$, et al. Optimizing the communication with cancer patients during the COVID-19 pandemic: patient perspectives. Patient Prefer Adherence 2020; 14: 1205-1212.

23. El Gohary GM, Hashmi S, Styczynski J, Kharfan-Dabaja MA, Alblooshi RM, de la Cámara R, et al. The risk and prognosis of COVID-19 infection in cancer patients: A systematic review and meta-analysis. Hematol Oncol Stem Cell Ther 2020 S1658-3876: 30122-30129.

24. Salunke AA, Nandy K, Pathak SK, Shah J, Kamani M, Kotakotta V, et al. Impact of COVID -19 in cancer patients on severity of disease and fatal outcomes: A systematic review and meta-analysis. Diabetes Metab Syndr: Clin Res Rev 2020; 14: 1431-1437.

25. Yarza R, Bover M, Paredes D, López-López F, Jara-Casas D, Castelo-Loureiro A, et al. SARS-CoV-2 infection in cancer patients undergoing active treatment: analysis of clinical features and predictive factors for severe respiratory failure and death Eur J Cancer 2020; 135: 242-250.

26. Kuderer NM, Choueiri TK, Shah DP, Shyr Y, Rubinstein SM, Rivera DR, et al. Clinical impact of COVID-19 on patients with cancer (CCC19): a cohort study. Lancet 2020; 395: 1907-1918.

27. 27. Urun Y, Hussain SA, Bakouny Z, Castellano D, Kılıçkap S, Morgan G, et al. Survey of the Impact of COVID-19 on Oncologist's Decision Making in Cancer. JCO Global Oncol 2020; 6: 1248-1257.

28. Angelis V, Tippu Z, Joshi K, Reis S, Gronthoud F, Fribbens C, et al. Defining the true impact of coronavirus disease 2019 in the at-risk population of patients with cancer. Eur J Cancer 2020; 136: 99-106. 